\title{
The Impact of Mesenchymal Stem Cell Source on Proliferation, Differentiation, Immunomodulation and Therapeutic Efficacy
}

\author{
Hui-Yun Cheng ${ }^{1}$, Nicolae Ghetu ${ }^{2}$, Christopher G Wallace ${ }^{3}$, Fu-Chan Wei ${ }^{1,3}$ and Shuen-Kuei Liao ${ }^{4,5 *}$ \\ ${ }^{1}$ Center for Vacularized Composite Allotransplantation, Chang Gung Memorial Hospital at Linkou, Taoyuan, Taiwan \\ 2University of Medicine and Pharmacy "Grigore T. Popa" lasi, Romania \& Plastic Surgery Unit, Regional Oncological Institute lasi, Romania \\ ${ }^{3}$ Department of Plastic and Reconstructive Surgery, Chang Gung Memorial Hospital at Linkou \& School of Medicine, Chang Gung University, Kweishan, Taoyuan, Taiwan \\ ${ }^{4}$ Graduate Institute of Cancer Biology and Drug Discovery and Center of Excellence for Cancer Research, Taipei Medical University, Taipei, Taiwan \\ ${ }^{5}$ Vectorite Biomedica Inc., Taipei, Taiwan
}

\begin{abstract}
Since their discovery almost 50 years ago, mesenchymal stem cells have shown great clinical potential in various clinical scenarios owing to their multilineage differentiation potential as well as immunomodulatory properties. However, recent studies indicate that properties of MSCs appear to be affected by factors such as their source. In this review, we focus on recent literature reporting direct comparisons of MSCs derived from different tissue sources, which include fetal MSCs from amniotic fluid, cord blood, umbilical cord and placenta, and adult MSCs from bone marrow, adipose tissue, heart, lung, synovial membrane and peripheral blood. It is demonstrated that MSCs from different sources showed variation in proliferation capacity, differentiation to various cells, immunomodulation capabilities, and efficacy of cell therapies in different scenarios. Furthermore, studies on MSCs derived from allogeneic or autologous origins revealed that allogeneic MSCs induced immunogenicity, potentially influencing their in vivo durability and thus efficacy when utilized as cell therapies: syngeneic (ie. autologous in inbred animals) or recipients' adipose-tissue-MSCs had better efficacy than allogeneic counterparts in inducing donor-specific tolerance in allotransplantation animal models. Therefore, careful consideration of the MSC source is recommended when a specific application is sought.
\end{abstract}

Keywords: Mesenchymal stem cell; Cell source; Differentiation; Immunomodulation; Cell therapy

\section{Introduction}

Mesenchymal stem cells (MSCs) were first isolated in 1968 by Friedenstein et al. [1] from bone marrow. It was later found that MSCs are multilineage progenitor cells with the capability to proliferate and differentiate in vitro [2]. The International Society for Cellular Therapy (ISCT) published minimum criteria to define MSCs, which included plastic adherence; fibroblast-like morphology; differentiation to osteoblasts, adipocytes, and chondroblasts; positive expression of CD105, CD73 and CD90; negative expression of CD45, CD34, CD14 or CD11b, CD79alpha or CD19, and HLA-DR surface molecules [3]. MSCs possess immunomodulatory properties that influence a variety of immune cell populations [4]. They have shown great potential for development in regenerative medicine, transplantation, and autoimmunity, to name only a few.

MSCs are present in all tissues [5]. They have, for example, been isolated from bone marrow, adipose tissue, periodontal ligament, synovial membrane and muscle [6], as well as fetal tissues such as placenta, amniotic fluid, umbilical cord, and Wharton's jelly. Whilst the ISCT-defined characteristics are mandatorily present, in vitro properties and surface molecular expressions appear to differ amongst MSCs from different origins [6,7]. This suggests that the origin of MSCs may affect cellular fates in vivo and/or their behavior when administered in vivo as therapeutic agents. Although research into MSCs is blooming, systematic investigations into how the sources of MSCs affect their behaviors are lacking. In the present paper, we review the literature that has reported side-by-side comparisons of MSCs derived from different origins, in order to help identify MSCs with specific properties for certain clinical applications.

Given the extensive literature in this field, this review has been limited principally to more recent papers and is not intended to be exhaustive. Throughout this paper, MSCs are derived from human tissues, unless otherwise specified, and MSCs will be identified with their corresponding origins as follows: AF-MSC (amniotic fluid), AMMSC (amnion), AT-MSC (adipose tissue), BM-MSC (bone marrow), CB-MSC (cord blood), CP-MSC (chorionic plate of placenta), H-MSC (heart), I-MSC (islet-derived), L-MSC (lung), OE-MSC (olfactory ectomesenchymal), PB-MSC (peripheral blood), PL-MSC (placenta), SM-MSC (skeletal muscle), SY-MSC (synovial membrane), UC-MSC (umbilical cord), and WJ-MSC (Wharton's jelly in umbilical cord).

\section{General Properties Including ex vivo Isolation and Proliferation}

Percentages of MSCs vary in different tissues. For example, the frequency of MSC in bone marrow is low $(0.001 \%-0.01 \%$ in mononuclear fraction), whereas adipose tissue contains about 500 -fold higher numbers of AT-MSCs [8,9]. The percentage of MSCs in amniotic fluid ranges from $0.9 \%$ to $1.5 \%$ [10]. Notably, however, isolation success of MSCs from bone marrow and adipose tissue was around $100 \%$ but ranged from $10 \%$ to $63 \%$ from umbilical cords $[7,11,12]$. Following isolation, cultured AT-MSCs reached confluence around day 15, but took 22 days for BM-MSCs to reach the same state [13]. For CB-MSCs, establishment of primary culture took approximately 30 days [14]. AT-

*Corresponding author: Prof. Shuen-Kuei Liao, Taipei Medical University, $250 \mathrm{Wu}$ Hsing St., Taipei 11031, Taiwan; Tel: +886-912-753-715; E-mail: liaosk@h.tmu.edu.tw

Received August 21, 2014; Accepted September 25, 2014; Published September 27, 2014

Citation: Cheng HY, Ghetu N, Wallace CG, Wei FC, Liao SK (2014) The Impact of Mesenchymal Stem Cell Source on Proliferation, Differentiation, Immunomodulation and Therapeutic Efficacy. J Stem Cell Res Ther 4: 237. doi:10.4172/2157-7633.1000237

Copyright: ( 2014 Cheng HY, et al. This is an open-access article distributed under the terms of the Creative Commons Attribution License, which permits unrestricted use, distribution, and reproduction in any medium, provided the original author and source are credited. 
MSCs also showed higher than average metabolic activity compared with BM-MSCs [9].

MSCs derived from fetal tissues (amniotic fluid, amniotic membrane, cord blood, umbilical cord) reportedly proliferated faster than those from adult tissues (bone marrow and adipose tissue) [1518]. The average doubling time of AF-MSCs and BM-MSCs was 1.6 and 3.75 days, respectively [10]. Interestingly, CB-MSCs showed more than a two-fold increase in proliferation at each subcultivation up to passage 14, while proliferation of BM-MSCs markedly reduced especially after the $10^{\text {th }}$ passage [14]. Donor age appears to impact on the growth rate of MSCs, since cells from newborn skin grew faster than those isolated from adult skin [19]. However, AT-MSCs isolated from 8-week old mice exhibited significantly shorter doubling times than their counterparts from 4-week old mice. Interestingly, this trend was the opposite of that observed for BM-MSCs [20]. Self-renewal of MSCs in vitro is not unlimited. AF-MSC, for example, can be maintained for 29 passages without any visible morphological changes whereas BMMSCs could be expanded for, at most, 12 passages before showing morphological alterations consistent with aged cells [17].

Fetal tissue-derived stem cells also differ from one another. Zhu et al. demonstrated that UC-MSCs displayed higher proliferative capacity, shorter doubling time, lower rate of apoptosis, and more mitotic activity than MSCs from placenta (PL-MSCs) [21]. Transmission electron microscopy revealed that PL-MSCs may have better adhesion capability than UC-MSCs. Similarly, AF-MSCs and WJ-MSCs were found to reach adherence at $2.7 \pm 1.6$, and $6.5 \pm 1.8$ days, respectively [22]. WJ-MSCs demonstrated superior proliferation potential and required less time to double in population compared to AT-MSCs [23]. Atomic force microscopy revealed that UC-MSCs have superior mass transport and cell migration capabilities than PL-MSCs [21].

The inspection of gene expression profiles reveals that MSCs appear to be specialized, at least in part, according to their source(s). Hsieh et al. reported that WJ-MSCs expressed more angiogenesis and growthrelated genes, whereas the gene expression pattern of BM-MSCs was significantly closer to that of osteoblasts [24]. Such differences appear to be reflected in the higher proliferative potential of WJ-MSCs and in the better osteogenic potential of BM-MSCs [24]. In contrast, H-MSCs (from heart) showed higher levels of cardiovascular related markers such as myosin light chain-2a, miR-126 and miR-146a [25].

\section{Differentiation}

In addition to the ability of MSCs to differentiate to other mesenchymal cell lineages, the in vitro capability of MSCs to transdifferentiate to endo/ectodermal lineages is important in regenerative medicine.

Although the ability to differentiate to osteoblasts, adipocytes, and chondroblasts is a defining feature of MSCs, it is known that MSCs from different tissue sources show bias in their differentiation patterns. For example, AT-MSCs had inferior osteogenic and chondrogenic potential compared to BM-MSCs [13,26,27]. Synthesis of collagen II and proteoglycans was only found in growth factor-treated BMMSCs but not AT-MSCs [28]. MSCs from peripheral blood displayed less osteogenic and adipogenic differentiation, in addition to a more chondrogenic capacity than BM-MSCs [29]. CB-MSCs and PLMSCs had less adipogenic capability and produced fewer and smaller lipid vacuoles than BM-MSCs and AT-MSCs [11,30]. Some reports suggested that $\mathrm{CB}-\mathrm{MSCs}$ lacked adipogenic differentiation potential $[7,12]$. Interestingly, although CB-MSCs displayed chondrogenic potential, they differentiated to fibrocartilage with a distinctly different morphology to that which BM-MSCs and PL-MSCs differentiated to [7]. Furthermore, MSCs from fetal lung and placenta showed lower chondrogenic potential compared to MSCs derived from fetal or adult bone marrow [31]. Diekman et al. demonstrated that BMMSCs and AT-MSCs proceeded to differential chondrogenesis in response to differing culture parameters, such as the presence of serum, growth factors, or the composition of scaffold [32]. In terms of osteogenesis, fetal MSCs produced more calcium and showed higher levels of osteogenic-specific gene expression than adult BM-MSCs. Interestingly, a hierarchy in oeteogenesis potential was found in fetal MSCs with different sources as follows: $\mathrm{BM}>$ blood $>$ liver [33].

MSCs demonstrate versatility in multilineage differentiation, implicating great clinical potential for MSCs in replacement/ regeneration of diseased tissues/cells. For instance, AT-MSCs and BMMSCs have comparable potential to differentiate towards functional hepatocytes expressing key metabolic enzymes such as cytochrome P450s [34]. Additionally, Zheng et al. reported that AF-MSCs had greater differentiation potential toward hepatocytes than BM-MSCs [17]. On the other hand, PL-MSCs produced more hepatogenic cytokines, such as HGF, than BM-MSCs and AT-MSCs [35].

For generating pancreatic islet cells in vitro, BM-MSCs were compared with islet-derived stem cells (I-MSCs). I-MSCs can be considered partially committed and show very low adipogenic differentiation potential. Both BM-MSCs and I-MSCs can differentiate to islet-like cells (ILCs), although glucose-induced insulin produced by BM-MSCs was significantly lower than from I-MSCs [36]. AT-MSCs may also differentiate to ILCs, but with a lower capacity compared to BM-MSCs [37]. On the other hand, primitive stromal cells from umbilical cord (UC-PSCs) formed larger ILC clusters and produced about 2.5 fold more insulin than BM-MSCs upon differentiation. Concurrently, more viable cells and less apoptosis were found in differentiated UC-PSC culture [38].

MSCs can be induced to neural stem cells (forming neurospheres, NS, in culture) and thus may have therapeutic potential to treat nerve injury or neuronal degenerative diseases. NSs derived from AF-MSCs (AF-NSs) were larger and proliferated at a higher rate than those from BM-MSCs, in addition to greater expression of neuronal stemness markers. Furthermore, AF-NSs differentiate to more neurons and glial cells upon terminal differentiation [39]. WJ-MSCs (from Wharton's jelly) were also reported to be induced to neural progenitors with better efficiency than either BM-MSCs or AT-MSCs [40]. However, Datta et al. demonstrated that WJ-MSCs and BM-MSCs had comparable potential to differentiate to dopaminergic neurons [41]. In their animal study, Zhang et al. showed that NSs derived from AT-MSCs had greater expansion and differentiation abilities than those from BM-MSCs [42].

Sources of MSCs were shown to influence differentiation potential to other lineages. UC-MSCs had significantly higher tubule length, diameter and area than BM-MSCs after endothelial differentiation [43]. AT-MSCs had better differentiation capacity to sinus-like cells than BM-MSCs from the same donor [44]. Rat MSCs from skeletal muscle (SM-MSCs) showed better myogenesis potential and higher expression of myoblast markers than AT-MSCs and BM-MSCs [45], although human AT-MSCs showed more myogenic differentiation than BM-MSCs [46]. Interestingly, choice of cell culture media also affected level of the skeletal muscle marker desmin expressed by the differentiated AT-MSCs [46]. On the other hand, fetal MSCs from umbilical cord, bone marrow, and amniotic membranes demonstrated potential to differentiate to functional cardiomyocytes, although adult counterparts from bone marrow and adipose tissue did not [47]. 
Citation: Cheng HY, Ghetu N, Wallace CG, Wei FC, Liao SK (2014) The Impact of Mesenchymal Stem Cell Source on Proliferation, Differentiation, Immunomodulation and Therapeutic Efficacy. J Stem Cell Res Ther 4: 237. doi:10.4172/2157-7633.1000237

Page 3 of 8

\section{Immunomodulation}

A prominent feature of MSCs is their ability to immunomodulate various immune cells, including T cells, B cells, dendritic cells, NK cells and macrophages. This research area has been reviewed extensively [4]; only reports that have focused on comparing MSCs from different origins are included in this section.

Melief et al. systematically compared AT-MSCs and BM-MSCs from age-matched donors [8]. It was found that AT-MSCs have stronger immunosuppressive effects than BM-MSCs on anti-CD3/ CD28-induced peripheral PBMC proliferation. An equivalent suppressive effect induced by BM-MSCs could be achieved by just one third of the number of AT-MSCs. Similarly, AT-MSCs were more suppressive than BM-MSCs on differentiation of monocytes to dendritic cells. Such differences correlated well with cytokine profiles. The presence of AT-MSCs led to less production of IFN- $\gamma$ and higher levels of IL-10 in anti-CD3/CD28-stimulated PBMCs and stimulated monocyte culture, respectively. MSCs also attenuated the expression of the costimulatory molecule CD86 in stimulated monocyte culture [48]. Furthermore, mitogen-stimulated immunoglobulin production in PBMCs was suppressed more by AT-MSCs than BM-MSCs [13]. MSCs from other adult tissues, such as olfactory ectomesenchymal (OEMSCs), heart (H-MSCs), and lung (L-MSCs) have been demonstrated to have in vitro immunosuppressive functions [49]. Compared to BM-MSCs, H-MSCs and L-MSCs preferentially suppressed T cell proliferation, whereas OE-MSCs had stronger effects on both $\mathrm{T}$ cell and NK cell proliferation. Interestingly, suppression on B cell proliferation was much more evident when the MSCs were primed with the inflammatory cytokines IFN- $\gamma$ and TNF- $\alpha$. Primed OE-MSCs and L-MSCs showed stronger B cell suppression than BM-MSCs with priming [49]. These immunomodulatory functions were found to be sustained for BM-MSCs and AT-MSCs, even with differentiation [50].

Fetal MSCs shared similar immunosuppressive functions with adult MSCs. Mitogen-stimulated PBMC proliferation can be suppressed by CB-MSCs and WJ-MSCs to a level comparable to that by adult BM-MSCs [51]. Anti-CD3/CD28-stimulated CD4+ and CD8 ${ }^{+}$ T cell proliferation was also suppressed by BM-MSCs and CB-MSCs to a similar level, which was lower than that achieved by PL-MSCs. Such effects were correlated with increases in levels of IL-10, IFN- $\gamma$, and generation of cell subsets with $\mathrm{CD} 4{ }^{+} \mathrm{CD} 25^{+} \mathrm{CTLA}-4^{+}$regulatory phenotype [52]. Lee et al. demonstrated that although MSCs derived from chorionic placenta (CP-MSCs) showed similar capability in suppression of $\mathrm{T}$ cell proliferation to BM-MSCs, higher expression level of HLA-G along with anti-inflammatory cytokines such as IL-4 and IL-13 may provide CP-MSCs with additional immunomodulatory advantages [53]. It is thought that the immunomodulatory functions of MSCs may directly relate to levels of prostaglandin-2 (PGE2) [54,55]. For example, MSCs derived from amniotic fetal membranes displayed more suppression of T-lymphocyte proliferation and higher levels of PGE-2 than counterparts from chorion [56]. Additionally, WJ-MSCs were found by Najar et al. to display suppressive effects on mitogenstimulated $\mathrm{T}$ cell proliferation when the cell number was $1 / 40$ of $\mathrm{T}$ cells [57]. However, significant suppression was achieved at $1 / 20$ and $1 / 8$ of T cells for AT-MSCs and BM-MSCs, respectively. Elevated expression of leukemia inhibitory factor (LIF) may have a causative relationship to suppression of $\mathrm{T}$ cell proliferation, since addition of LIF antibody abolished the effects [57].

Anti-inflammatory effects were evaluated with coculturing of MSCs with LPS-treated alveolar macrophages. It was found CB-MSCs expressed lower level of proinflammatory cytokines IL-1 $\beta$, IL- 6 and
IL-8 than BM-MSCs and AT-MSCs. Higher expression of the upstream angiopoietin-1 in CB-MSCs was demonstrated to be critical [58].

Chan et al. adopted microarray analysis to compare gene expression in fetal versus adult MSCs [15]. Functional network analysis of 950 out of 31099 genes showed eight immune response pathways were differentially regulated, including Th17 differentiation, CD40 signaling, macrophage migration inhibitory factor, and histamine $\mathrm{H} 1$ receptor signaling. As IL-6 participated in all eight pathways, the level of IL-6 was monitored for in vitro MSC and phytohaemagglutinin (PHA)stimulated PBMC coculture. Significantly higher increases of IL-6 level following PHA stimulation was found in fetal MSC compared to adult MSC cocultures, corresponding to the suppressive potential on PHAstimulated PBMC proliferation [15]. This highlights the importance of the role of IL- 6 in regulating the immunosuppressive functions of MSCs.

PHA induced phenotypic changes upon immune cells in PBMCs in addition to influencing proliferation. It was demonstrated that ATMSCs had stronger effects on T cell activation than WJ-MSCs and BMMSCs, such that most $\mathrm{T}$ cells remained inactivated when cocultured with AT-MSC even with PHA stimulation. For B cells, acquisition of lymphoblast phenotype was inhibited by BM-MSCs and AT-MSCs whereas WJ-MSCs had no effects [59]. Furthermore, activation of NK cells was strongly inhibited by all three of these MSCs. It is therefore clear that MSCs derived from different tissues may inflict distinct functions on specific cell types.

\section{Cell Therapy}

MSCs have been applied as cell-based therapies for different disease conditions such as graft versus host disease, bone defects and myocardial infarction, to name a few [60]. Sources of MSCs have been found to correlate with therapeutic efficiency. For example, Zhou et al. demonstrated that xenotransplantation of human AT-MSCs to rats with spinal cord injury enhanced more angiogenesis and axonal regeneration in addition to better functional recovery than BM-MSCs [61]. The significantly higher levels of neurotropic factors that ATMSCs induced, including BDNF, VEGF, and HGF, may play a role. Dogs that had MSCs administered at 1 week after spinal cord injury showed significant improvement in functional recovery, although no differences were found among AT-MSCs, BM-MSCs, WJ-MSCs, and CB-MSCs [62]. Results from a mouse stroke model in vivo showed that AT-MSCs significantly reduced volume of infarction and swelling, in addition to improving neurological function compared to BM-MSCs [20].

MSCs have been explored as a therapeutic approach for cancers of poor prognosis, such as glioblastoma multiforme (GBM) [63]. In a mouse xenotransplantation model, co-transplanted CB-MSCs inhibited GBM growth, whereas AT-MSCs promoted tumor growth. AT-MSCs enhanced vessel formation and suppressed apoptosis compared to CBMSCs. Whilst higher expression of endogenous CXCL12 in AT-MSCs was shown to play a significant role, higher expressions of angiogenic factors such as VEGF, angiopoietin-1, PDGF, IGF-1 in AT-MSCs may also be relevant [64].

MSCs have been shown to promote wound healing as well [65]. Comparison of human AT-MSCs, BM-MSCs and AM-MSCs on repairing mouse wounds showed that AT-MSCs had the most pronounced effects on wound healing. More migration of dermal fibroblasts and higher expression of growth factors induced by ATMSCs were observed [66]. 
The in vivo oseteogenesis potential of human MSCs was evaluated in a rat critical-sized femoral defect model and it was found that fetal UC-MSCs and CB-MSCs, and adult AT-MSCs and BM-MSCs, showed comparable osteogenesis potential [67]. Similar potential for in vivo osteogenesis was also found for canine AT-MSCs, BM-MSCs, CBMSCs, and WJ-MSCs [68].

Infused MSCs in in vivo disease/injury models may not necessarily repair damage by regeneration. De Coppi et al. evaluated in vivo myogenesis following bladder injury and found that both BM- and AF-MSCs engaged significantly in preventing cryo-injury induced hypertrophy of surviving muscle cells [69]. This was supported by data showing that AT-MSCs and BM-MSCs protected cardiomyoblasts from cell death induced by ischemia-reperfusion to a similar degree in vitro [70]. Additionally, MSCs from cardiac tissues were proven to show higher cardiomyogenic differentiation in vivo than BM-MSCs following injection to infarcted left ventricle [25]. BM-MSCs were shown to differentiate preferentially to smooth muscle cells, in contrast to AT-MSCs, which differentiated preferentially to endothelial cells and cardiomyocytes in a rat cardiac injury model [71]. In contrast, human AT-MSCs were shown to have better myoregeneration potential than BM- and SY- counterparts when treating cardiotoxin-damaged tibialis anterior muscle [72]. These results suggest that the intrinsic properties of MSCs interact with the microenvironment in vivo and lead to different outcomes following cell therapy.

Proper homing of MSCs to the site of interest is critical following administration. Direct comparison between WJ-MSCs and BMMSCs showed that WJ-MSCs expressed higher levels of angiogenic chemokines such as CXCL1, CXCL, CXCL5, CXCL6, and CXCL8; and angiogenic growth factors like VEGF-D, PDGF-AA, TGF- $\beta 2$, bFGF and HGF [73]. In light of these findings, WJ-MSC may be a better choice to prevent or reduce fibrosis and scarring in tissue injury.

MSCs have been shown to prolong allograft survival in the setting of solid organ transplantation (SOT) [74]. Furthermore, when allografts containing multiple types of tissues, termed vascularized composite allotransplant (VCA such as face transplants or limb transplants), were transplanted, MSCs were shown to induce donor-specific tolerance and prolong VCA survival [75-79]. BM-MSCs and AT-MSCs were the two types that were mostly utilized, although they have not yet been compared side-by-side in terms of influencing VCA survival. Interestingly, Saka et al. showed that AT-MSCs, especially when intravenously administered, induced a lower level of IgG antibodies against xenoantigens compared to BM-MSCs in vivo [80].

\section{Allogeneic versus Autologous Sources of MSCs}

There appears to be potential for allogeneic MSCs (allo-MSCs) to serve as an "off the shelf" therapeutic option, since these cells may be isolated and cultured from healthy donors in advance. This is in contrast to autologous MSCs (auto-MSCs), which need to be prepared per individual and may not be suitable or available for some acute conditions. Furthermore, MSCs with certain origins, such as fetal tissues like amniotic fluid and umbilical cord, are most likely allogeneic. Previously, all MSCs were regarded as having low immunogenicity, since they all expressed only low levels of MHC class I and II, and exerted immunosuppressive functions in vitro and in vivo. However, recent studies have suggested that allo-MSCs may not be as immunoprivileged as previously suggested. Schu et al. showed in rats that allo-MSCs induced alloantibodies with the potential to activate complement-mediated lysis in vivo [81]. Intra-striatal administration of allo-MSCs elicited a cellular immune response; this was, however, not strong enough to clear the administered cells [82]. Differentiation may elicit immunogenicity by increasing expression of MHC I and MHC II, and stimulating lymphocyte proliferation [83,84]. AlloMSCs are also able to educate $\mathrm{CD}^{+} \mathrm{T}$ cells with cytotoxicity against themselves. Interestingly, BM-MSCs elicited a higher level of lysis than AT-MSCs [9]. It seems that different factors such as the disease model, route of administration, and experimental species have effects on the immunogenicity of allo-MSCs in vivo [85]. Interestingly, a randomized clinical trial comparing allo-MSCs and auto-MSCs for treatment of ischemic cardiomyopathy showed low immunogenicity of allo-MSCs in addition to comparable efficacies of both cell populations [86].

MSCs have been shown to target primary and metastatic tumors. Hung et al. showed with SCID mice subcutaneously transplanted with human colon cancer cells that intravenously infused MSCs migrated and engrafted to microscopic tumor lesions [87]. By taking advantage of such an unique feature in addition to relatively low immunogenicity, allogeneic MSCs may therefore be used as a novel, universal delivery vehicle of cytokine genes such as IFN- $\gamma$ or drugs to induce tumor dormancy or other antitumor therapeutic effects $[88,89]$.

On the other hand, autologous BM-MSCs were found to have better efficacy in improving acute kidney injury [90]. Both auto- and allo- MSCs have been applied in transplantation studies with promising results [91-93]. We have employed syngeneic (identical to autologous from inbred animals) AT-MSCs in conjunction with anti-lymphocyte serum and short-term cyclosporin in rat osteomyocutaneous VCA and successfully induced donor-specific tolerance [76,94]. A side-by-side comparison with the same animal model and immunosuppression regimen showed that syngeneic or recipient AT-MSCs had superior efficacy with $66 \%$ tolerance rate as compared to their allogeneic counterparts with 33\% (Figure 1). Auto-MSCs have been applied to a clinical VCA case and enabled minimal maintenance levels of immunosuppressants without acute rejection at twenty months after transplantation [95]. Given that the presence of a variety of diseases may not affect the efficacy of MSCs [96-100], more potential clinical applications with autologous MSCs are no doubt underway.

\section{Conclusions and Perspectives}

MSCs have great clinical potential for treating various disease conditions. Although MSCs derived from different tissues may have a common origin, they appear to have acquired specific characteristics due to interactions with the microenvironment of various tissues. This article has reviewed recent knowledge of the influence of MSC sources on their properties in proliferation, differentiation, immunomodulation, and cell therapy efficacy. As shown in Table 1, the general trend regarding MSC sources and their properties may be summarized as follows:

(1) Fetal MSCs in general have better proliferation capability than adult MSCs.

(2) MSCs derived from a specific tissue are better suited to differentiate to cells of that tissue. For example, BM-MSCs have better osteogenesis capability than other MSCs in comparison. Similar trends are found in I-MSCs for islet differentiation and SM-MSCs for myogenesis.

(3) Fetal MSCs or AT-MSCs are better choices than BM-MSCs if immunomodulatory function is important.

(4) AT-MSCs showed great potential as a cell therapy agent in vivo in general. Further studies are warranted to analyze the feasibility of AT-MSC as a treatment option for carcinomas. 
Citation: Cheng HY, Ghetu N, Wallace CG, Wei FC, Liao SK (2014) The Impact of Mesenchymal Stem Cell Source on Proliferation, Differentiation, Immunomodulation and Therapeutic Efficacy. J Stem Cell Res Ther 4: 237. doi:10.4172/2157-7633.1000237

Page 5 of 8

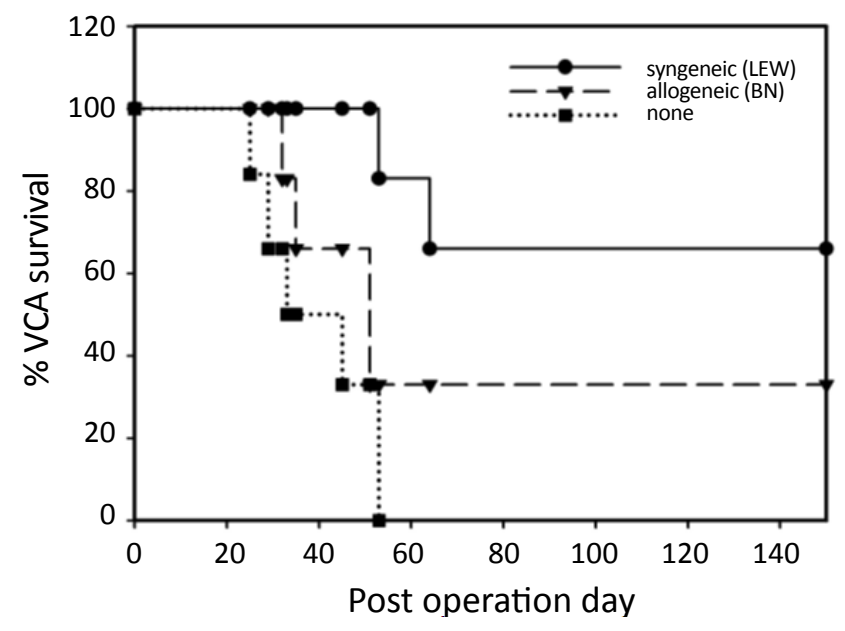

Figure 1: Syngeneic AT-MSCs prolongs survival of vascularized composite allotransplants (VCA) more than allogeneic AT-MSCs. The experimental model was rat osteomyocutaneous flap allotransplantation from BN rat to LEW rat as described in [76]. The immunosuppression regimen included antilymphocyte serum at post-operation day (POD) -1, 10, cyclosporine 16 $\mathrm{mg} / \mathrm{kg}$ from day $0-10$, in addition to AT-MSCs at POD 1. It was demonstrated that donor-specific tolerance developed in the recipients with long-term surviving VCA. The Kaplan-Meier survival analysis showed the median survival time for syngeneic and allogeneic AT-MSC groups was $>150$ and 51 days, respectively.

\begin{tabular}{|c|c|c|c|}
\hline Superior & Inferior & Parameter in comparison & Reference \\
\hline \multicolumn{4}{|c|}{ Basic Properties (in vitro) } \\
\hline AT- & BM- & MSC frequency & {$[8,9]$} \\
\hline AT- & BM- & metabolic activity & [8] \\
\hline AF- & BM- & proliferation & {$[10]$} \\
\hline WJ & AT & proliferation & [23] \\
\hline UC- & PL- & proliferation & [21] \\
\hline WJ- & BM- & proliferation & [24] \\
\hline PL- & UC- & adhesion capability & [21] \\
\hline AF- & WJ- & adhesion capability & [22] \\
\hline UC- & PL- & mass transport and cell migration & [21] \\
\hline \multicolumn{4}{|c|}{ Differentiation (in vitro) } \\
\hline BM- & WJ- & osteogenesis & [24] \\
\hline BM- & AT- & osteogenesis, chondrogenesis & {$[13,26,27]$} \\
\hline BM- & PB- & osteogenesis, adipogenesis & [29] \\
\hline BM-, AT- & CB-, PL- & adipogenesis & {$[11,30]$} \\
\hline PB- & BM- & chondrogenesis & [29] \\
\hline BM (fetal and adult) & $\begin{array}{l}\text { L (fetal), } \\
\text { PL- }\end{array}$ & chondrogeneisis & [31] \\
\hline AF- & BM- & hepatocyte differentiation & [17] \\
\hline I- & BM- & islet differentation & [36] \\
\hline UC-PSC & BM- & islet differentation & [38] \\
\hline BM- & AT- & islet differentation & [37] \\
\hline AF- & BM- & neural stem cell differentiation & [39] \\
\hline WJ- & BM- or AT- & $\begin{array}{l}\text { neural progenitor cell } \\
\text { differentiation }\end{array}$ & {$[40]$} \\
\hline AT- & BM- & neural stem cell differentiation & {$[42]$} \\
\hline UC- & BM- & endothelial differentiation & [43] \\
\hline AT- & BM- & sinus-like cell differentiation & {$[44]$} \\
\hline SM- & AT-, or BM- & myogenesis (rat) & [45] \\
\hline AT- & BM- & myogenesis & {$[46]$} \\
\hline
\end{tabular}

\begin{tabular}{|c|c|c|c|}
\hline \multicolumn{4}{|c|}{ Immunomodulatory (in vitro) } \\
\hline AT- & BM- & $\begin{array}{c}\text { suppressing -CD3/CD28 induced } \\
\text { PBMC proliferation }\end{array}$ & [8] \\
\hline AT- & BM- & $\begin{array}{c}\text { suppressing dendritic cell } \\
\text { differentiation }\end{array}$ & [48] \\
\hline AT- & BM- & $\begin{array}{l}\text { suppressing mitogen-stimulated } \\
\text { Ig production }\end{array}$ & [13] \\
\hline H-, L- OE- & BM- & suppressing $\mathrm{T}$ cell activation & [49] \\
\hline OE- & BM- & suppressing NK cell activation & [49] \\
\hline OE-, L- (primed) & $\begin{array}{c}\text { BM- } \\
\text { (primed) }\end{array}$ & suppressing B cell activation & [49] \\
\hline CB, WJ-, BM- & -- & $\begin{array}{l}\text { suppressing mitogen-stimulated } \\
\text { PBMC proliferation }\end{array}$ & [51] \\
\hline PL- & BM-, CB- & $\begin{array}{l}\text { suppressing } \alpha-C D 3 / C D 28 \\
\text { induced T cell proliferation }\end{array}$ & [52] \\
\hline CP-, BM- & -- & suppressing $\mathrm{T}$ cell activation & [53] \\
\hline WJ- & BM-, AT- & $\begin{array}{l}\text { suppressing mitogen-stimulated } \\
\text { T cell proliferation }\end{array}$ & [57] \\
\hline CB- & BM-, AT- & anti-inflammatory effects & [58] \\
\hline AT- & WJ-, BM- & $\begin{array}{l}\text { suppressing PHA-induced T cell } \\
\text { activation }\end{array}$ & [59] \\
\hline AT-, WJ-, BM- & -- & suppressing NK cell activation & [59] \\
\hline \multicolumn{4}{|c|}{ Cell Therapy (in vivo) } \\
\hline AT- & BM- & $\begin{array}{c}\text { regeneration following spinal cord } \\
\text { injury (rat) }\end{array}$ & [61] \\
\hline AT-, BM-, WJ-, CB- & -- & $\begin{array}{c}\text { early recovery from spinal cord } \\
\text { injury (canine) }\end{array}$ & [62] \\
\hline AT- & BM- & improvement from stroke (mouse) & [20] \\
\hline CB- & AT- & inhibit GBM growth (mouse) & [63] \\
\hline AT- & BM-, AM- & wound closure (mouse) & [66] \\
\hline UC-, CB-, AT-, BM- & -- & $\begin{array}{l}\text { osteogenesis following bone } \\
\text { defect(rat) }\end{array}$ & [67] \\
\hline CB-, WJ-, AT-, BM- & -- & in vivo osteogenesis (canine) & [68] \\
\hline $\mathrm{H}-$ & BM- & cardiomyogenesis (rat) & [25] \\
\hline AT- & BM-, SY- & $\begin{array}{l}\text { skeletal muscle regeneration } \\
\text { (mouse) }\end{array}$ & [72] \\
\hline AT- & BM- & xeno-antibody production (rat) & [80] \\
\hline
\end{tabular}

Note: The comparison demonstrated in the indicated reference is shown. The one with stronger effect on the specific parameter is listed at the column of "Superior". If all MSCs had comparable effects, they are all listed in the column of "Superior". Abbreviation of MSCs (source): AF-MSC (amniotic fluid), AM-MSC (amnion), ATMSC (adipose tissue), BM-MSC (bone marrow), CB-MSC (cord blood), CP-MSC (chorionic plate of placenta), H-MSC (heart), I-MSC (islet-derived), L-MSC (lung), OE-MSC (olfactory ectomesenchymal), PB-MSC (peripheral blood), PL-MSC (placenta), SM-MSC (skeletal muscle), SY-MSC (synovial membrane), UC-MSC (umbilical cord), and WJ-MSC (Wharton's jelly in umbilical cord).

Table 1: Summary of the effects of MSC source on different parameters.

Furthermore, comparison of MSCs derived from allogeneic or autologous origins revealed that allo-MSCs may be immunogenic and cell therapy efficacies may be affected. This was illustrated by our results that syngeneic AT-MSCs had better efficacy than allogeneic AT-MSCs in inducing donor-specific tolerance to a VCAs in rats [76] (Figure 1). The wide range of biological properties of MSCs has shown great clinical potential. However, their properties can be influenced by factors such as their origins. Studies of detailed molecular events governing the variations in MSC properties are in need to decipher how environmental cues affect MSC behaviors, including the physiological and/or pathological milieu that MSCs reside in, physical and/or chemical stresses, and in vitro culture conditions. Our review has shown MSCs derived from various tissue origins have their own advantages/disadvantages in different aspects. Careful consideration of MSC sources with regard to specific applications is warranted.

\section{Acknowledgements}

We acknowledge the financial support of the Ministry of Health and Welfare, 
Citation: Cheng HY, Ghetu N, Wallace CG, Wei FC, Liao SK (2014) The Impact of Mesenchymal Stem Cell Source on Proliferation, Differentiation, Immunomodulation and Therapeutic Efficacy. J Stem Cell Res Ther 4: 237. doi:10.4172/2157-7633.1000237

Taiwan (MOHW103-TD-B-111-01), the National Science Council (NSC99-2314B-182-016-MY2), and Chang Gung Memorial Hospital, Taiwan (CMRPG3A0433).

\section{References}

1. Friedenstein AJ, Petrakova KV, Kurolesova Al, Frolova GP (1968) Heterotopic of bone marrow. Analysis of precursor cells for osteogenic and hematopoietic tissues. Transplantation 6: 230-247. [PubMed]

2. Caplan Al (1991) Mesenchymal stem cells. J Orthop Res 9: 641-650. [PubMed]

3. Dominici M, Le Blanc K, Mueller I, Slaper-Cortenbach I, Marini F, et al. (2006) Minimal criteria for defining multipotent mesenchymal stromal cells. The International Society for Cellular Therapy position statement. Cytotherapy 8: 315-317. [PubMed]

4. Chen PM, Yen ML, Liu KJ, Sytwu HK, Yen BL (2011) Immunomodulatory properties of human adult and fetal multipotent mesenchymal stem cells. $\mathrm{J}$ Biomed Sci 18: 49. [PubMed]

5. da Silva Meirelles L, Chagastelles PC, Nardi NB (2006) Mesenchymal stem cells reside in virtually all post-natal organs and tissues. J Cell Sci 119: 22042213. [PubMed]

6. Orbay $\mathrm{H}$, Tobita M, Mizuno $\mathrm{H}$ (2012) Mesenchymal stem cells isolated from adipose and other tissues: basic biological properties and clinical applications. Stem Cells Int 2012: 461718. [PubMed]

7. Montesinos JJ, Flores-Figueroa E, Castillo-Medina S, Flores-Guzman P, Hernandez-Estevez E, et al. (2009) Human mesenchymal stromal cells from adult and neonatal sources: comparative analysis of their morphology, immunophenotype, differentiation patterns and neural protein expression. Cytotherapy 11: 163-176. [PubMed]

8. Roemeling-van Rhijn M, Reinders ME, Franquesa M, Engela AU, Korevaar SS, et al. (2013) Human allogeneic bone marrow and adipose tissue derived mesenchymal stromal cells induce CD8+ cytotoxic T cell reactivity. J Stem Cell Res Ther 3: 004. [PubMed]

9. Melief SM, Zwaginga JJ, Fibbe WE, Roelofs H (2013) Adipose tissue-derived multipotent stromal cells have a higher immunomodulatory capacity than their bone marrow-derived counterparts. Stem Cells Transl Med 2: 455-463. [PubMed]

10. Roubelakis MG, Pappa KI, Bitsika V, Zagoura D, Vlahou A, et al. (2007) Molecular and proteomic characterization of human mesenchymal stem cells derived from amniotic fluid: comparison to bone marrow mesenchymal stem cells. Stem Cells Dev 16: 931-952. [PubMed]

11. Rebelatto CK, Aguiar AM, Moretao MP, Senegaglia AC, Hansen P, et al (2008) Dissimilar differentiation of mesenchymal stem cells from bone marrow, umbilical cord blood, and adipose tissue. Exp Biol Med (Maywood) 233: $901-$ 913. [PubMed]

12. Kern S, Eichler H, Stoeve J, Kluter H, Bieback K (2006) Comparative analysis of mesenchymal stem cells from bone marrow, umbilical cord blood, or adipose tissue. Stem Cells 24: 1294-1301. [PubMed]

13. Bochev I, Elmadjian G, Kyurkchiev D, Tzvetanov L, Altankova I, et al. (2008) Mesenchymal stem cells from human bone marrow or adipose tissue differently modulate mitogen-stimulated B-cell immunoglobulin production in vitro. Cell Biol Int 32: 384-393. [PubMed]

14. Son BR, Marquez-Curtis LA, Kucia M, Wysoczynski M, Turner AR, et al. (2006) Migration of bone marrow and cord blood mesenchymal stem cells in vitro is regulated by stromal-derived factor-1-CXCR4 and hepatocyte growth factor-Cmet axes and involves matrix metalloproteinases. Stem Cells 24: 1254-1264. [PubMed]

15. Chan CK, Wu KH, Lee YS, Hwang SM, Lee MS, et al. (2012) The comparison of interleukin 6-associated immunosuppressive effects of human ESCs, fetaltype MSCs, and adult-type MSCs. Transplantation 94: 132-138. [PubMed]

16. Wei X, Peng G, Zheng S, Wu X (2012) Differentiation of umbilical cord mesenchymal stem cells into steroidogenic cells in comparison to bone marrow mesenchymal stem cells. Cell Prolif 45: 101-110. [PubMed]

17. Zheng YB, Gao ZL, Xie C, Zhu HP, Peng L, et al. (2008) Characterization and hepatogenic differentiation of mesenchymal stem cells from human amniotic fluid and human bone marrow: a comparative study. Cell Biol Int 32: 14391448. [PubMed]

18. Choudhery MS, Badowski M, Muise A, Harris DT (2013) Comparison of human mesenchymal stem cells derived from adipose and cord tissue. Cytotherapy 15: 330-343. [PubMed]
19. Al-Nbaheen M, Vishnubalaji R, Ali D, Bouslimi A, Al-Jassir F, et al. (2013) Human stromal (mesenchymal) stem cells from bone marrow, adipose tissue and skin exhibit differences in molecular phenotype and differentiation potential Stem Cell Rev 9: 32-43. [PubMed]

20. Ikegame $Y$, Yamashita K, Hayashi S, Mizuno H, Tawada M, et al. (2011) Comparison of mesenchymal stem cells from adipose tissue and bone marrow for ischemic stroke therapy. Cytotherapy 13: 675-685. [PubMed]

21. Zhu SF, Zhong ZN, Fu XF, Peng DX, Lu GH, et al. (2013) Comparison of cell proliferation, apoptosis, cellular morphology and ultrastructure between human umbilical cord and placenta-derived mesenchymal stem cells. Neurosci Lett 541: 77-82. [PubMed]

22. Bai J, Hu Y, Wang YR, Liu LF, Chen J, et al. (2012) Comparison of human amniotic fluid-derived and umbilical cord Wharton's Jelly-derived mesenchyma stromal cells: Characterization and myocardial differentiation capacity. J Geriatr Cardiol 9: 166-171. [PubMed]

23. Christodoulou I, Kolisis FN, Papaevangeliou D, Zoumpourlis V (2013) Comparative evaluation of human mesenchymal stem cells of fetal (Wharton's jelly) and adult (adipose tissue) origin during prolonged in vitro expansion: considerations for cytotherapy. Stem Cells Int 2013: 246134. [PubMed]

24. Hsieh JY, Fu YS, Chang SJ, Tsuang YH, Wang HW (2010) Functional module analysis reveals differential osteogenic and stemness potentials in human mesenchymal stem cells from bone marrow and Wharton's jelly of umbilical cord. Stem Cells Dev 19: 1895-1910. [PubMed]

25. Rossini A, Frati C, Lagrasta C, Graiani G, Scopece A, et al. (2011) Human cardiac and bone marrow stromal cells exhibit distinctive properties related to their origin. Cardiovasc Res 89: 650-660. [PubMed]

26. Im GI, Shin YW, Lee KB (2005) Do adipose tissue-derived mesenchymal stem cells have the same osteogenic and chondrogenic potential as bone marrowderived cells? Osteoarthritis Cartilage 13: 845-853. [PubMed]

27. Vishnubalaji R, Al-Nbaheen M, Kadalmani B, Aldahmash A, Ramesh T (2012) Comparative investigation of the differentiation capability of bone-marrowand adipose-derived mesenchymal stem cells by qualitative and quantitative analysis. Cell Tissue Res 347: 419-427. [PubMed]

28. Afizah H, Yang Z, Hui JH, Ouyang HW, Lee EH (2007) A comparison between the chondrogenic potential of human bone marrow stem cells (BMSCs) and adipose-derived stem cells (ADSCs) taken from the same donors. Tissue Eng 13: 659-666. [PubMed]

29. Fu WL, Zhang JY, Fu X, Duan XN, Leung KK, et al. (2012) Comparative study of the biological characteristics of mesenchymal stem cells from bone marrow and peripheral blood of rats. Tissue Eng Part A 18: 1793-1803. [PubMed]

30. Barlow S, Brooke G, Chatterjee K, Price G, Pelekanos R, et al. (2008) Comparison of human placenta- and bone marrow-derived multipotent mesenchymal stem cells. Stem Cells Dev 17: 1095-1107. [PubMed]

31. Bernardo ME, Locatelli F, Fibbe WE (2009) Mesenchymal stromal cells. Ann N Y Acad Sci 1176: 101-117. [PubMed]

32. Diekman BO, Rowland CR, Lennon DP, Caplan AI, Guilak F (2010) Chondrogenesis of adult stem cells from adipose tissue and bone marrow: induction by growth factors and cartilage-derived matrix. Tissue Eng Part A 16: 523-533. [PubMed]

33. Guillot PV, De Bari C, Dell'Accio F, Kurata H, Polak J, et al. (2008) Comparative osteogenic transcription profiling of various fetal and adult mesenchymal stem cell sources. Differentiation 76: 946-957. [PubMed]

34. Talens-Visconti R, Bonora A, Jover R, Mirabet V, Carbonell F, et al. (2006) Hepatogenic differentiation of human mesenchymal stem cells from adipose tissue in comparison with bone marrow mesenchymal stem cells. World $\mathrm{J}$ Gastroenterol 12: 5834-5845. [PubMed]

35. Lee HJ, Jung J, Cho KJ, Lee CK, Hwang SG, et al. (2012) Comparison of in vitro hepatogenic differentiation potential between various placenta-derived stem cells and other adult stem cells as an alternative source of functional hepatocytes. Differentiation 84: 223-231. [PubMed]

36. Zanini C, Bruno S, Mandili G, Baci D, Cerutti F, et al. (2011) Differentiation of mesenchymal stem cells derived from pancreatic islets and bone marrow into islet-like cell phenotype. PLoS One 6: e28175. [PubMed]

37. Marappagounder D, Somasundaram I, Dorairaj S, Sankaran RJ (2013) Differentiation of mesenchymal stem cells derived from human bone marrow and subcutaneous adipose tissue into pancreatic islet-like clusters in vitro. Cell Mol Biol Lett 18: 75-88. [PubMed] 
Citation: Cheng HY, Ghetu N, Wallace CG, Wei FC, Liao SK (2014) The Impact of Mesenchymal Stem Cell Source on Proliferation, Differentiation, Immunomodulation and Therapeutic Efficacy. J Stem Cell Res Ther 4: 237. doi:10.4172/2157-7633.1000237

38. Wu LF, Wang NN, Liu YS, Wei X (2009) Differentiation of Wharton's jelly primitive stromal cells into insulin-producing cells in comparison with bone marrow mesenchymal stem cells. Tissue Eng Part A 15: 2865-2873. [PubMed]

39. Yan ZJ, Hu YQ, Zhang HT, Zhang P, Xiao ZY, et al. (2013) Comparison of the neural differentiation potential of human mesenchymal stem cells from amniotic fluid and adult bone marrow. Cell Mol Neurobiol 33: 465-475. [PubMed]

40. Balasubramanian S, Thej C, Venugopal P, Priya N, Zakaria Z, et al. (2013) Higher propensity of Wharton's jelly derived mesenchymal stromal cells towards neuronal lineage in comparison to those derived from adipose and bone marrow. Cell Biol Int 37: 507-515. [PubMed]

41. Datta I, Mishra S, Mohanty L, Pulikkot S, Joshi PG (2011) Neuronal plasticity of human Wharton's jelly mesenchymal stromal cells to the dopaminergic cell type compared with human bone marrow mesenchymal stromal cells. Cytotherapy 13: 918-932. [PubMed]

42. Zhang HT, Liu ZL, Yao XQ, Yang ZJ, Xu RX (2012) Neural differentiation ability of mesenchymal stromal cells from bone marrow and adipose tissue: a comparative study. Cytotherapy 14: 1203-1214. [PubMed]

43. Chen MY, Lie PC, Li ZL, Wei X (2009) Endothelial differentiation of Wharton's jelly-derived mesenchymal stem cells in comparison with bone marrow-derived mesenchymal stem cells. Exp Hematol 37: 629-640. [PubMed]

44. Yang J, Song T, Wu P, Chen Y, Fan X, et al. (2012) Differentiation potential of human mesenchymal stem cells derived from adipose tissue and bone marrow to sinus node-like cells. Mol Med Rep 5: 108-113. [PubMed]

45. Meligy FY, Shigemura K, Behnsawy HM, Fujisawa M, Kawabata M, et al. (2012) The efficiency of in vitro isolation and myogenic differentiation of MSCs derived from adipose connective tissue, bone marrow, and skeletal muscle tissue. In Vitro Cell Dev Biol Anim 48: 203-215. [PubMed]

46. Stern-Straeter J, Bonaterra GA, Juritz S, Birk R, Goessler UR, et al. (2014) Evaluation of the effects of different culture media on the myogenic differentiation potential of adipose tissue- or bone marrow-derived human mesenchymal stem cells. Int J Mol Med 33: 160-170. [PubMed]

47. Ramkisoensing AA, Pijnappels DA, Askar SF, Passier R, Swildens J, et al. (2011) Human embryonic and fetal mesenchymal stem cells differentiate toward three different cardiac lineages in contrast to their adult counterparts. PLoS One 6: e24164. [PubMed]

48. Ivanova-Todorova E, Bochev I, Mourdjeva M, Dimitrov R, Bukarev D, et al. (2009) Adipose tissue-derived mesenchymal stem cells are more potent suppressors of dendritic cells differentiation compared to bone marrow-derived mesenchymal stem cells. Immunol Lett 126: 37-42. [PubMed]

49. Di Trapani M, Bassi G, Ricciardi M, Fontana E, Bifari F, et al. (2013) Comparative study of immune regulatory properties of stem cells derived from different tissues. Stem Cells Dev 22: 2990-3002. [PubMed]

50. Niemeyer P, Kornacker M, Mehlhorn A, Seckinger A, Vohrer J, et al. (2007) Comparison of immunological properties of bone marrow stromal cells and adipose tissue-derived stem cells before and after osteogenic differentiation in vitro. Tissue Eng 13: 111-121. [PubMed]

51. Yoo KH, Jang IK, Lee MW, Kim HE, Yang MS, et al. (2009) Comparison of immunomodulatory properties of mesenchymal stem cells derived from adult human tissues. Cell Immunol 259: 150-156. [PubMed]

52. Castro-Manrreza ME, Mayani H, Monroy-Garcia A, Flores-Figueroa E, ChavezRueda K, et al. (2014) Human mesenchymal stromal cells from adult and neonatal sources: a comparative in vitro analysis of their immunosuppressive properties against T cells. Stem Cells Dev 23: 1217-1232. [PubMed]

53. Lee JM, Jung J, Lee HJ, Jeong SJ, Cho KJ, et al. (2012) Comparison of immunomodulatory effects of placenta mesenchymal stem cells with bone marrow and adipose mesenchymal stem cells. Int Immunopharmacol 13: 219224. [PubMed]

54. Najar M, Raicevic G, Boufker HI, Fayyad Kazan H, De Bruyn C, et al. (2010) Mesenchymal stromal cells use PGE2 to modulate activation and proliferation of Iymphocyte subsets: Combined comparison of adipose tissue, Wharton's Jelly and bone marrow sources. Cell Immunol 264: 171-179. [PubMed]

55. Yanez R, Oviedo A, Aldea M, Bueren JA, Lamana ML (2010) Prostaglandin $E 2$ plays a key role in the immunosuppressive properties of adipose and bone marrow tissue-derived mesenchymal stromal cells. Exp Cell Res 316: 31093123. [PubMed]

56. Yamahara K, Harada K, Ohshima M, Ishikane S, Ohnishi S, et al. (2014)
Comparison of angiogenic, cytoprotective, and immunosuppressive properties of human amnion- and chorion-derived mesenchymal stem cells. PLoS One 9: e88319. [PubMed]

57. Najar M, Raicevic G, Boufker HI, Fayyad-Kazan H, De Bruyn C, et al. (2010) Adipose-tissue-derived and Wharton's jelly-derived mesenchymal stromal cells suppress lymphocyte responses by secreting leukemia inhibitory factor. Tissue Eng Part A 16: 3537-3546. [PubMed]

58. Jin HJ, Bae YK, Kim M, Kwon SJ, Jeon HB, et al. (2013) Comparative analysis of human mesenchymal stem cells from bone marrow, adipose tissue, and umbilical cord blood as sources of cell therapy. Int J Mol Sci 14: 17986-18001. [PubMed]

59. Ribeiro A, Laranjeira P, Mendes S, Velada I, Leite C, et al. (2013) Mesenchymal stem cells from umbilical cord matrix, adipose tissue and bone marrow exhibit different capability to suppress peripheral blood $B$, natural killer and $T$ cells. Stem Cell Res Ther 4: 125. [PubMed]

60. Hao L, Sun H, Wang J, Wang T, Wang M, et al. (2012) Mesenchymal stromal cells for cell therapy: besides supporting hematopoiesis. Int J Hematol 95: 3446. [PubMed]

61. Zhou Z, Chen Y, Zhang H, Min S, Yu B, et al. (2013) Comparison of mesenchymal stromal cells from human bone marrow and adipose tissue for the treatment of spinal cord injury. Cytotherapy 15: 434-448. [PubMed]

62. Ryu HH, Kang BJ, Park SS, Kim Y, Sung GJ, et al. (2012) Comparison of mesenchymal stem cells derived from fat, bone marrow, Wharton's jelly, and umbilical cord blood for treating spinal cord injuries in dogs. J Vet Med Sci 74: 1617-1630. [PubMed]

63. Kauer TM, Figueiredo JL, Hingtgen S, Shah K (2012) Encapsulated therapeutic stem cells implanted in the tumor resection cavity induce cell death in gliomas. Nat Neurosci 15: 197-204. [PubMed]

64. Akimoto K, Kimura K, Nagano M, Takano S, To'a Salazar G, et al. (2013) Umbilical cord blood-derived mesenchymal stem cells inhibit, but adipose tissue-derived mesenchymal stem cells promote, glioblastoma multiforme proliferation. Stem Cells Dev 22: 1370-1386. [PubMed]

65. Chen L, Tredget EE, Liu C, Wu Y (2009) Analysis of allogenicity of mesenchymal stem cells in engraftment and wound healing in mice. PLoS One 4: e7119. [PubMed]

66. Liu X, Wang Z, Wang R, Zhao F, Shi P, et al. (2013) Direct comparison of the potency of human mesenchymal stem cells derived from amnion tissue, bone marrow and adipose tissue at inducing dermal fibroblast responses to cutaneous wounds. Int J Mol Med 31: 407-415. [PubMed]

67. Jo CH, Yoon PW, Kim H, Kang KS, Yoon KS (2013) Comparative evaluation of in vivo osteogenic differentiation of fetal and adult mesenchymal stem cell in rat critical-sized femoral defect model. Cell Tissue Res 353: 41-52. [PubMed]

68. Kang BJ, Ryu HH, Park SS, Koyama Y, Kikuchi M, et al. (2012) Comparing the osteogenic potential of canine mesenchymal stem cells derived from adipose tissues, bone marrow, umbilical cord blood, and Wharton's jelly for treating bone defects. J Vet Sci 13: 299-310. [PubMed]

69. De Coppi P, Callegari A, Chiavegato A, Gasparotto L, Piccoli M, et al. (2007) Amniotic fluid and bone marrow derived mesenchymal stem cells can be converted to smooth muscle cells in the cryo-injured rat bladder and prevent compensatory hypertrophy of surviving smooth muscle cells. J Urol 177: 369376. [PubMed]

70. Szepes M, Benko Z, Cselenyak A, Kompisch KM, Schumacher U, et al. (2013) Comparison of the direct effects of human adipose- and bone-marrow-derived stem cells on postischemic cardiomyoblasts in an in vitro simulated ischemiareperfusion model. Stem Cells Int 2013: 178346.

71. lop L, Chiavegato A, Callegari A, Bollini S, Piccoli M, et al. (2008) Different cardiovascular potential of adult- and fetal-type mesenchymal stem cells in a rat model of heart cryoinjury. Cell Transplant 17: 679-694. [PubMed]

72. de la Garza-Rodea AS, van der Velde-van Dijke I, Boersma H, Goncalves MA, van Bekkum DW, et al. (2012) Myogenic properties of human mesenchymal stem cells derived from three different sources. Cell Transplant 21: 153-173. [PubMed]

73. Balasubramanian S, Venugopal P, Sundarraj S, Zakaria Z, Majumdar AS, et al. (2012) Comparison of chemokine and receptor gene expression between Wharton's jelly and bone marrow-derived mesenchymal stromal cells. Cytotherapy 14: 26-33. [PubMed] 
Citation: Cheng HY, Ghetu N, Wallace CG, Wei FC, Liao SK (2014) The Impact of Mesenchymal Stem Cell Source on Proliferation, Differentiation, Immunomodulation and Therapeutic Efficacy. J Stem Cell Res Ther 4: 237. doi:10.4172/2157-7633.1000237

Page 8 of 8

74. English K, Wood KJ (2013) Mesenchymal stromal cells in transplantation rejection and tolerance. Cold Spring Harb Perspect Med 3: a015560. [PubMed]

75. Kuo YR, Chen CC, Goto S, Huang YT, Wang CT, et al. (2012) Immunomodulatory effects of bone marrow-derived mesenchymal stem cells in a swine hemi-facial allotransplantation model. PLoS One 7: e35459. [PubMed]

76. Cheng HY, Ghetu N, Huang WC, Wang YL, Wallace CG, et al. (2014) Syngeneic adipose-derived stem cells with short-term immunosuppression induce vascularized composite allotransplantation tolerance in rats. Cytotherapy 16 369-380. [PubMed]

77. Plock JA, Schnider JT, Solari MG, Zheng XX, Gorantla VS (2013) Perspectives on the use of mesenchymal stem cells in vascularized composite allotransplantation. Front Immunol 4: 175. [PubMed]

78. Lin JY, Liao SK (2014) New perspectives in tolerance induction for vascularized composite allotransplantation. Surgery: Curr Res 4: 196.

79. Huang WC, Lin JY, Wallace CG, Wei FC, Liao SK (2012) Improving the safety of tolerance induction: chimerism and cellular co-treatment strategies applied to vascularized composite allografts. Clin Dev Immunol 2012: 107901. [PubMed]

80. Saka Y, Furuhashi K, Katsuno T, Kim H, Ozaki T, et al. (2011) Adipose-derived stromal cells cultured in a low-serum medium, but not bone marrow-derived stromal cells, impede xenoantibody production. Xenotransplantation 18: 196208. [PubMed]

81. Schu S, Nosov M, O'Flynn L, Shaw G, Treacy O, et al. (2012) Immunogenicity of allogeneic mesenchymal stem cells. J Cell Mol Med 16: 2094-2103. [PubMed]

82. Camp DM, Loeffler DA, Farrah DM, Borneman JN, LeWitt PA (2009) Cellular immune response to intrastriatally implanted allogeneic bone marrow stromal cells in a rat model of Parkinson's disease. J Neuroinflammation 6: 17. [PubMed]

83. Huang XP, Sun Z, Miyagi Y, McDonald Kinkaid H, Zhang L, et al. (2010) Differentiation of allogeneic mesenchymal stem cells induces immunogenicity and limits their long-term benefits for myocardial repair. Circulation 122: 24192429. [PubMed]

84. Mukonoweshuro B, Brown CJ, Fisher J, Ingham E (2014) Immunogenicity of undifferentiated and differentiated allogeneic mouse mesenchymal stem cells. $\mathrm{J}$ Tissue Eng 5: 2041731414534255. [PubMed]

85. Griffin MD, Ryan AE, Alagesan S, Lohan P, Treacy O, et al. (2013) Anti-donor immune responses elicited by allogeneic mesenchymal stem cells: what have we learned so far[quest]. Immunol Cell Biol 91: 40-51. [PubMed]

86. Hare JM, Fishman JE, Gerstenblith G, DiFede Velazquez DL, Zambrano JP, et al. (2012) Comparison of allogeneic vs. autologous bone marrow-derived mesenchymal stem cells delivered by transendocardial injection in patients with ischemic cardiomyopathy: the POSEIDON randomized trial. JAMA 308: 23692379. [PubMed]

87. Hung SC, Deng WP, Yang WK, Liu RS, Lee CC, et al. (2005) Mesenchymal stem cell targeting of microscopic tumors and tumor stroma development monitored by noninvasive in vivo positron emission tomography imaging. Clin Cancer Res 11: 7749-7756. [PubMed]

88. Latorre-Romero C, Marin-Yaseli MR, Belmar-Lopez C, del Moral R, Marijuan PC, et al. (2011) Using living cells to transport therapeutic genes for cancer treatment. Clin Transl Oncol 13: 10-17. [PubMed]

89. Chou AS, Chen HC, Li CR, Hsieh CH, Ting LL, et al. (2011) Tumor dormancy resulting from subcutaneous injection to SCID mice with cultured nasopharyngeal carcinoma cells is mediated via IFN-gamma induction of a highly differentiated phenotype. Cancer Biother Radiopharm 26: 417-426. [PubMed]

90. Togel F, Cohen A, Zhang P, Yang Y, Hu Z, et al. (2009) Autologous and allogeneic marrow stromal cells are safe and effective for the treatment of acute kidney injury. Stem Cells Dev 18: 475-485. [PubMed]

91. Tan J, Wu W, Xu X, Liao L, Zheng F, et al. (2012) Induction therapy with autologous mesenchymal stem cells in living-related kidney transplants: a randomized controlled trial. JAMA 307: 1169-1177. [PubMed]

92. Peng Y, Ke M, Xu L, Liu L, Chen X, et al. (2013) Donor-derived mesenchymal stem cells combined with low-dose tacrolimus prevent acute rejection after renal transplantation: a clinical pilot study. Transplantation 95: 161-168. [PubMed]

93. Alagesan S, Griffin MD (2014) Autologous and allogeneic mesenchymal stem cells in organ transplantation: what do we know about their safety and efficacy? Curr Opin Organ Transplant 19: 65-72. [PubMed]

94. Ramirez AE, Cheng HY, Lao WW, Wang YL, Wen CJ, et al. (2014) A nove rat full thickness hemi-abdominal wall/hindlimb osteomyocutaneous combined flap: influence of allograft mass and vascularized bone marrow content on vascularized composite allograft survival. Transpl Int. 27: 977-986. [PubMed]

95. Del Bene M, Di Caprio AP, Melzi ML, Pioltelli PE, Bonomi S (2013) Autologous mesenchymal stem cells as a new strategy in immunosuppressant therapy in double hand allotransplantation. Plast Reconstr Surg 131: 305-307. [PubMed]

96. Bocelli-Tyndall C, Bracci L, Spagnoli G, Braccini A, Bouchenaki M, et al. (2007) Bone marrow mesenchymal stromal cells (BM-MSCs) from healthy donors and auto-immune disease patients reduce the proliferation of autologous- and allogeneic-stimulated lymphocytes in vitro. Rheumatology (Oxford) 46: 403408. [PubMed]

97. Wang J, Liao L, Wang S, Tan J (2013) Cell therapy with autologous mesenchymal stem cells-how the disease process impacts clinical considerations. Cytotherapy 15: 893-904. [PubMed]

98. Zhao Z, Tang X, You Y, Li W, Liu F, et al. (2006) Assessment of bone marrow mesenchymal stem cell biological characteristics and support hemotopoiesis function in patients with chronic myeloid leukemia. Leuk Res 30: 993-1003. [PubMed]

99. Zhao ZG, Liang Y, Li K, Li WM, Li QB, et al. (2007) Phenotypic and functional comparison of mesenchymal stem cells derived from the bone marrow of normal adults and patients with hematologic malignant diseases. Stem Cells Dev 16: 637-648. [PubMed]

100. Murphy MB, Moncivais K, Caplan Al (2013) Mesenchymal stem cells: environmentally responsive therapeutics for regenerative medicine. Exp Mol Med 45: e54. [PubMed] 